\title{
Impact of COVID-19 Pandemic on COMPI Fertility Problem Stress Scale and the State-Trait Anxiety Scale in Patients Undergoing IVF/ICSI
}

\author{
Arzu YURCI', Saban KARAYAGIZ²
}

Kayseri, Turkey

\begin{abstract}
OBJECTIVE: This study aimed to investigate the effect of the COVID-19 outbreak on infertile couples dealing with stress and anxiety during in vitro fertilization treatment.

STUDY DESIGN: 252 infertile patients who applied for in vitro fertilization treatment were included in this cross-sectional study. Data were collected via four data collection tools including socio-demographic form, COVID-19 Inventory (COVID-I), COMPI fertility problem stress scale (COMPI-FPSS), and statetrait anxiety scale. Data analysis was conducted by SPSS statistical software included statistical analysis such as averages, standard deviations, correlation, regression, and t-test.

RESULTS: Both negative and weak correlations were found between COMPI fertility problem stress scale and subscales of state-trait anxiety scale as well as the total score of state-trait anxiety scale. In terms of socio-demographic characteristics of the participants and their responses in state-trait anxiety scale and ISS forms, the correlation coefficients were also so low. The results also showed that public officials, health professionals, and educators showed lower state-trait anxiety scale (stress-related anxiety) scores.
\end{abstract}

CONCLUSION: During the COVID-19 pandemic, there was an increase in spontaneous pregnancy expectations. Although participants were mostly stressed because of the COVID-19 outbreak, they didn't change their in vitro fertilization treatment plans during the outbreak.

Keywords: Anxiety, COVID-19, Infertility, Reproductive health, SARS-CoV-2, Stress

Gynecol Obstet Reprod Med 2021;27(1):49-55

\section{Introduction}

Infertility treatment has always been a great challenge for couples due to its complex and challenging process (1). It is defined as the failure in getting pregnant for 12 months despite regular unprotected sexual intercourse. Although infertility is

\footnotetext{
${ }^{1}$ Memorial Kayseri Hospital IVF-Center, Kayseri, Turkey

${ }^{2}$ Nuh Naci Yazgan University, Faculty of Science, Department of Psychology, Kayseri, Turkey

Address of Correspondence: Arzu Yurci

Memorial Kayseri Hospital IVF Center,

Gevher Nesibe Mahallesi Cicek Sokak No:10

Kayseri, Turkey

arzuyurci@yahoo.com
}

Submitted for Publication: 04.02.2021 Revised for Publication: 06.02.2021

Accepted for Publication: 12.03.2021 Online Published: 01.04.2021

ORCID IDs of the authors: $\quad$ AY: 0000-0003-4808-9019

SK: 0000-0002-6914-4630

\begin{tabular}{|c|c|}
\hline Quick Response Code: & Access this article online \\
\cline { 2 - 2 } & Website: www.gorm.com.tr \\
& e- mail: info@gorm.com.tr \\
\cline { 2 - 3 } & DOI:10.21613/GORM.2021.1187 \\
\hline
\end{tabular}

How to cite this article: Yurci A. and Karayagiz S. Impact of COVID-19 pandemic on COMPI Fertility Problem Stress Scaleand the State-Trait Anxiety Scale in Patients Undergoing IVF/ICSI. Gynecol Obstet Reprod Med. 2021;27(1):49-55 not a life-threatening health problem, it may negatively affect psychological wellbeing by depression, sexual distress, and anxiety-related problems in both men and women (1-3). In addition to underlying disorders, stress-related factors, smoking, excessive drinking, and prolonged exposure to high mental stress, chemicals, radiation, or heavy electromagnetic exposure were also proved to greatly impact the fertility of the women (4-6). In vitro fertilization (IVF) is known as one of the main methods leading to high stress and anxiety for couples especially for women.

The COVID-19 outbreak appeared in early 2020 and spread across the world rapidly in the last six months. As of today, more than 90 million people are currently infected and of them, approximately 2 million people have died from the Coronavirus (7). Initially, studies showed that it could affect only individuals older than 50 years, but recent studies indicated that the chances of getting infected by this disease do not depend on the age of a person. Additionally, several studies have been conducted to investigate the impacts of the diseases on older people, pregnant women, and children. Recent studies showed that Coronavirus disease greatly influences the health life of people and their mental status. It also poses a 
great potential risk for reproductive health, including the reproductive system and its functioning and embryo development (8-11).

While postponing IVF treatments in the group of infertile patients aged 35 years and over during the pandemic causes anxiety, the expectation that the chance of spontaneous pregnancy will increase in younger infertile patients has come to the fore. The main reason for this expectation is that couples stay at home for a long time due to street restrictions. However, as there was no expected regression in the pandemic, some changes were recommended in the guidelines on IVF treatments. Postponement of non-urgent diagnostic procedures and elective surgical operations are the leading ones (12). Both the European Society of Human Reproduction and Embryology and the American Society for Reproductive Medicine suggested discontinuing new fertility procedures, such as ovulation induction, and intrauterine insemination as well as non-urgent gamete cryopreservation, cancelation of all fresh or frozen embryo transfers (13). Exceptions were infertile couples currently "in-cycle" or requiring urgent fertility preservation due to cancer treatment.

A recent study conducted on the knowledge, attitude, anxiety, and perceived mental health care need during the COVID-19 outbreak included a total of 662 individuals at various places and ages in India (14). The findings showed that most the educated people are aware of this infectious disease. However, most people require an awareness program to tackle mental issues during COVID-19. It was also emphasized that this pandemic resulted in high mortality worldwide with the high media attention as well as distributing anxiety significantly among the public across the world. Since World Health Organization (WHO) decreed a public health emergency of international importance for the sixth time in its history in January 2020, medical societies in women health and infertility suggested that the patients with infertility should consider delaying their pregnancy during the COVID-19 outbreak $(15,16)$. Other important recommendations included halting infertility treatments including reproductive treatments, ovulation induction, in vitro fertilization across the world. Beyond all these cautions and recommendations, there existed no known impacts of COVID-19 on fertility treatment except any types of stress and mental issues of the couples during the therapy sessions.

Various researches have been conducted regarding the effects of COVID-19 on the IVF treatment process (17-22). A recent study suggested IVF units manage such crises including COVID-19 as well as all of the healthcare professionals be given the confidence by their employees about their jobs. During the COVID-19 outbreak, such mandatory changes including IVF and related procedures are required (19). In view of the above facts, this study was designed to investigate how the COVID-19 pandemic affects the lives of the couples un- dergoing an IVF treatment especially when the impacts of the prohibitions and restrictions due to the COVID-19 and treatment process remain unclear. In this survey study, in addition to recording the socio-demographic characteristics of the patients, the following research questions were asked to be answered.

1- Has the pandemic affected the IVF treatment process?

2- Has the frequency of sexual intercourse changed during the period of staying at home with social isolation due to the COVID-19?

3- Has there been any change in the period of talking about IVF and pregnancy during the pandemic?

4- Is there a relationship between the IVF stress scale and the state anxiety inventories?

5- Has there a relationship between the items of the COVID-19 scale and the state anxiety scale? In light of the results obtained from the survey, the effects of the COVID-19 pandemic on the anxiety states of IVF patients were discussed in detail.

\section{Material and Method}

This cross-sectional survey study was designed as a quantitative research approach and specifically, the descriptive methodology to investigate the influences of the Coronavirus outbreak on a group of infertile couples' stress and anxiety during infertility treatment. Two hundred and fifty-two women were purposefully selected from the patients who consulted Memorial Kayseri Hospital IVF-Center for infertility treatment. Approval for the study was granted by Nuh Naci Yazgan University Research Ethics Committee (approval number: 2020/3). A random sampling method was used to select the participants. The study was conducted with a prospective approach and the participants volunteered to partake in the study. All of the participants completed a consent form that clearly explains conditions, requirements, purposes, and special information regarding the study and data collection process.

Four data collection forms and inventories were utilized for the study investigation. A socio-demographic form consisted of occupation, age, and monthly income, duration of the marriage, and education status for the socio-demographic features of the participants. The COVID-19 Inventory included various information regarding the participants' perspectives and impact for the time beings of the epidemic such as frequency of sexual relationship, following the COVID-19 news on $\mathrm{TV}$, treatment ideas, and expectation of getting pregnant during the pandemic. These data collection tools were prepared by the researchers. Other data collection inventories were the COMPI Fertility Problem Stress Scale (COMPIFPSS) and the State-Trait Anxiety Scale (STAI). The COMPI- 
FPSS is a scale consisting of 14 questions with 5 and 4 point Likert-type answers regarding the participants' reactions, physical and mental situations (23). COMPI-FPSS basically assesses the impacts of the fertility process and treatment for infertile couples. The last data collection tool, STAI, is a psychological inventory based on a 4-point Likert scale and measures two types of anxiety, state anxiety and trait anxiety about an event (24). STAI consists of 40 statements with two subscales, 20 items allocated to each of the S-Anxiety (current state) and T-Anxiety (general state). It was developed as a measurement inventory to gather data regarding how a person feels at the moment in the first 20 items and how they generally feel in the second 20 items. The total ranges of the scores for each subscale are between 20 and 80, the higher score signifying higher levels of anxiety. A cut point of 40 was suggested for the clinical diagnosis. 48 points and above is considered high anxiety. This study was conducted in accordance with the Declaration of Helsinki and informed consent was obtained from all participants.

\section{Statistical analysis}

Statistical analyses were performed with the SPSS 20.0 software. Descriptive statistics were given as the mean, standard deviation, minimum, and maximum for numerical variables and as numbers and percentages for categorical vari- ables. A paired sample t-test was used to compare dependent groups when the differences in numerical variables met the normal distribution conditions, and the Wilcoxon test was used when the normal distribution conditions were not met. Pearson's correlation analysis was used for detecting correlation parameters. A p-value of $<.05$ was considered to be statistically significant.

\section{Results}

The results of the research findings are discussed in the following manner. Initially, the socio-demographic features of the participants are presented and briefly discussed. The relationships between their socio-demographic features, reactions to the COVID-19 pandemic, infertility stress, and state anxiety levels were recorded and discussed. Survey data obtained from participants were analyzed to show statistical correlations, regressions, and statistical significance. As can be seen in Table I where socio-demographic data are analyzed approximately half of the patients were between the ages of 31 and 40, and approximately two-thirds were college graduates. Despite the participation of many occupational groups, the majority of them were healthcare workers.

After the statistical analysis of the survey data, we deter-

Table I: Demographic characteristics of the survey participants

\begin{tabular}{|c|c|c|c|}
\hline Sociodemographic Feature & Classification & Frequency & $\%$ \\
\hline \multirow{3}{*}{ Women Age (year) } & $21-30$ & 75 & 29.8 \\
\hline & $31-40$ & 124 & 49.2 \\
\hline & $41-45$ & 53 & 21.0 \\
\hline \multirow{3}{*}{ Employment (Y/N) } & Yes & 147 & 58.3 \\
\hline & No & 90 & 35.7 \\
\hline & Quit due to COVID-19 & 15 & 6.0 \\
\hline \multirow{3}{*}{ Education status (grad.) } & Elementary School & 10 & 4.0 \\
\hline & Secondary School & 52 & 20.6 \\
\hline & College & 190 & 75.4 \\
\hline \multirow{6}{*}{ Profession } & Teacher/Educator & 48 & 19.0 \\
\hline & Officer & 20 & 7.9 \\
\hline & Health Employee & 60 & 23.8 \\
\hline & Manager & 45 & 17.9 \\
\hline & Housewife & 21 & 8.4 \\
\hline & Other & 58 & 23.0 \\
\hline \multirow{4}{*}{ Total monthly income (TL) } & $0-2.500$ & 64 & 25.5 \\
\hline & $2.501-5.000$ & 53 & 21.0 \\
\hline & $5.001-10.000$ & 82 & 32.5 \\
\hline & $10.001-20.000$ & 53 & 21.0 \\
\hline \multirow{3}{*}{ Duration of marriage (year) } & $1-5$ & 75 & 29.8 \\
\hline & $6-10$ & 124 & 49.2 \\
\hline & $11-20$ & 53 & 21.0 \\
\hline
\end{tabular}


mined the following changes in the stress and anxiety of our patients who received infertility treatment during the COVID19 outbreak. We clearly showed that the COVID-19 pandemic negatively affected the psychological status of participants but no change regarding their income levels and their IVF plans. They mostly follow the COVID-19 news on media. They generally discussed their IVF treatments for between 1 and 2 hours during the lockdown periods. Also, they didn't postpone their IVF treatment plans due to the COVID-19 outbreak. They expected to experience spontaneous pregnancy during the outbreak.
In the second data collection tool, the participants responded to the items regarding the impacts of the COVID-19 epidemic on their economic status, IVF treatment, sexual life, and following the COVID-19 news. The participants answered a total of 12 items on the questionnaire with various Likert scales including Yes, No, decreased, and increased, none, no changed. The answers given by the participants to the 12 questions in the COVID-I questionnaire were analyzed according to the frequencies, percentages, and t-test (Table II). When the responses to COVID-I are analyzed according to the socio-demographic characteristics of the patients the answers given to

Table II: The descriptive statistics of the COVID-19 Inventory (COVID-I)

\begin{tabular}{|c|c|c|c|c|}
\hline Item & Classification & Frequency & $\%$ & $p^{*}$ \\
\hline \multirow[t]{3}{*}{ 1. How did the COVID-19 outbreak affect your economic status? } & Increased & 6 & 2.4 & 0.02 \\
\hline & Decreased & 116 & 46.0 & \\
\hline & No change & 130 & $51.6^{*}$ & \\
\hline \multirow[t]{3}{*}{ 2. How did the COVID19 outbreak affect your IVF treatment plans? } & Increased & 95 & $37.7^{*}$ & 0.01 \\
\hline & Decreased & 11 & 4.4 & \\
\hline & No change & 146 & $57.9^{*}$ & \\
\hline \multirow{3}{*}{$\begin{array}{l}\text { 3. Did COVID-19 outbreak affect the frequency of sexual intercourse with } \\
\text { your partner? }\end{array}$} & Increased & 72 & 28.6 & 0.34 \\
\hline & Decreased & 38 & 15.1 & \\
\hline & No change & 142 & 56.3 & \\
\hline \multirow{4}{*}{$\begin{array}{l}\text { 4. What is your weekly average frequency of sexual intercourse during } \\
\text { your stay at home due to the epidemic? }\end{array}$} & None & 21 & 8.3 & 0.56 \\
\hline & $1-2$ & 129 & 51.2 & \\
\hline & $3-4$ & 77 & 30.6 & \\
\hline & $5-6$ & 25 & 9.9 & \\
\hline \multirow[t]{2}{*}{ 5. Do you follow the news about IVF on TV, social media, etc.? } & Yes & 201 & $79.8^{*}$ & 0.04 \\
\hline & No & 51 & 20.2 & \\
\hline \multirow{4}{*}{$\begin{array}{l}\text { 6. If indicated yes on item } 5 \text {, how many hours do you spend with the } \\
\text { news per week? Otherwise, mark NA. }\end{array}$} & None & 51 & 20.2 & \\
\hline & $1-2$ & 167 & 66.3 & 0.60 \\
\hline & $3-4$ & 30 & 11.9 & \\
\hline & $5-6$ & 4 & 1.6 & \\
\hline \multirow[t]{3}{*}{ 7. Which media do you follow the news about COVID-19 most? } & TV & 115 & 45.6 & 0.40 \\
\hline & Social Media & 88 & 34.9 & \\
\hline & Web sites & 49 & 19.4 & \\
\hline \multirow{4}{*}{$\begin{array}{l}\text { 8. How long was the treatment discussed during the stay at home during } \\
\text { the COVID-19 outbreak? (Hour) }\end{array}$} & None & 48 & 19.0 & 0.33 \\
\hline & $1-2$ & 147 & 58.3 & \\
\hline & $3-4$ & 49 & 19.4 & \\
\hline & $5-6$ & 8 & 3.2 & \\
\hline \multirow{2}{*}{$\begin{array}{l}\text { 9. Was there an idea to completely cancel the treatment plan due to the } \\
\text { COVID-19 outbreak? }\end{array}$} & Yes & 75 & 29.8 & 0.21 \\
\hline & No & 177 & 70.2 & \\
\hline \multirow{2}{*}{$\begin{array}{l}\text { 10. Was there a desire for immediate treatment following the COVID-19 out- } \\
\text { break? }\end{array}$} & Yes & 156 & $61.9^{*}$ & 0.03 \\
\hline & No & 96 & 38.1 & \\
\hline \multirow{2}{*}{$\begin{array}{l}\text { 11. Do you think getting infected with the COVID-19 affects the chance } \\
\text { of getting pregnant? }\end{array}$} & Yes & 124 & 49.2 & 0.13 \\
\hline & No & 128 & 50.8 & \\
\hline \multirow{2}{*}{$\begin{array}{l}\text { 12. Has there been an increase in the expectation of spontaneous pregnancy } \\
\text { during the outbreak? }\end{array}$} & Yes & 104 & 41.3 & 0.02 \\
\hline & No & 148 & $58.7^{*}$ & \\
\hline
\end{tabular}

* Significant differences based on t-test $(p<0.05)$ 
the questions varied significantly according to the participants' education, employment, age, income, and duration of the marriage. When the answers to the questions in COVID-I were analyzed by t-test, it was found that the answers given to the following parameters were significantly different. We can list the different answers as follows; (i) The proportion of those who follow the news about the effects of the pandemic on IVF, (ii) the proportion of individuals who do not intend to quit IVF treatment due to the pandemic, (iii) the proportion of those who believe that the pandemic will affect their chances of conception, (iv) and the rate of those who believe that their chance of spontaneous pregnancy will increase during the pandemic. Interestingly, the percentage of those who believed that the pandemic would not affect IVF treatments was the common response of more than half of the participants.

Table III summarizes the descriptive statistical findings for the data collection inventories (STAI and COMPI-FPSS) utilized in this study. The subscales of the STAI, STAI-S, and STAI-T, as well as total scores of the STAI scale, were shown separately. The median value of the total STAI score was 96 (0.9). The median value of the STAI-S and STAI-T scores was recorded as 46 (7.6) and $48.5(0.5)$, respectively. The median value of the participants in terms of COMPI-FPSS score was recorded as 44 (12.4). The correlations between the STAI and COMPI-FPSS scores are presented in Table IV. There was a positive and significant correlation between the STAI T score and STAI S score. Similarly, a positive and significant correlation was found between the STAI total score and the STAI $\mathrm{S}$ and STAI T scores. A negative but insignificant correlation was found between COMPI-FPSS and STAI S, STATI T, and STAI total scores.

Table III: The descriptive statistics of the inventories

\begin{tabular}{lcc}
\hline Scale & Median (SD) & Range (Min-Max) \\
\hline STAI-S & $46(7.6)$ & $51(21-72)$ \\
STAI-T & $48.5(0.5)$ & $46(34-80)$ \\
STAI-Total & $96(0.9)$ & $88(55-143)$ \\
COMPI-FPSS & $44(12.4)$ & $42(14-60)$ \\
\hline
\end{tabular}

STAI-S: State-trait anxiety scale-current stage, STAI-T: State-trait anxiety scale-general stage, COMPI-FPSS: COMPI fertility problem stress scale

Table IV: Correlation (Pearson's) coefficients ( $r$ ) between STAI and ISS results

\begin{tabular}{lcccc}
\hline & STAI S & STAI T & $\begin{array}{c}\text { STAI } \\
\text { Total }\end{array}$ & $\begin{array}{c}\text { COMPI- } \\
\text { FPSS }\end{array}$ \\
\hline STAI S & 1 & & & \\
STAI T & $0.57^{*}$ & 1 & & \\
STAI Total & $0.88^{*}$ & $0.89^{*}$ & 1 & \\
COMPI-FPSS & -0.001 & -0.02 & -0.014 & 1 \\
\hline
\end{tabular}

STAI: State-trait anxiety scale, COMPI-FPSS: COMPI fertility problem stress scale

\section{Discussion}

Studies showed that the presence of psychological problems affects the therapeutic success of IVF (25-28). IVF treatment is complex and stressful and can have a negative impact on the emotional and psychological well-being of the couple. When the negative effects of the pandemic are added to the treatment process, the current picture becomes a stronger stress stimulus for the patient. The threshold for having anxiety for the STAI scale is 40 points or higher. Based on our study data, the mean scores of each STAI subscales were around 48 which $20 \%$ higher than the threshold. This result shows that the majority of the women had high levels of anxiety because of the COVID-19 pandemic during IVF treatment. In terms of socio-demographic characteristics of the participants and their responses in STAI and COMPI-FPSS forms, the correlation coefficients were so low that they could be ignored except for the employment status. Our result showed that public officials, health professionals, and educators showed lower STAI scores. On the other hand, housewives and managers showed higher levels of STAI scores and higher anxiety. The participants with higher levels of education were more affected by the COVID-19 outbreak regarding economic issues. Low-income families were less affected by the Coronavirus outbreak. Also, the families with higher education levels spent less time watching COVID-19 related news on media. Likewise, teachers, students, and health professionals follow the news about COVID-19 on websites and social media. These groups of participants were also more affected in terms of stress-related anxiety compared to managers and housewives. High-income participants said having bad sexual intercourse during the outbreak. Also, they follow the COVID-19 news more on websites and social media. They also believed that they have more chances of getting spontaneous pregnancy during the epidemic. The participants who don't follow the IVF news on media were feeling more stressed and having higher levels of anxiety. Similarly, the participants with the idea of not canceling IVF treatment during the epidemic had higher levels of anxiety. When considering research questions posed at the beginning of the investigation, only 11 out of 252 participants canceled IVF treatment, and pandemic slightly affected participants' infertility treatment plans. Most of the participants discussed and talked about IVF treatment and pregnancy for about 1-2 hours per week during the pandemic. We, therefore, couldn't find any significant correlation between infertility treatment and participant's anxiety levels from the data analysis. This result could be explained as the stress levels of the women on infertility treatment are not clear indicators for IVF-related anxiety.

When the results of our survey study were compared with different basic studies of similar quality in the literature, they were compatible with some and inconsistent with others (2528). A recent study by a Swedish group investigated the impact of depression, anxiety, and antidepressants before in vitro 
fertilization on pregnancy, live birth, and miscarriage rate in 23.557 nulliparous women undergoing their first IVF cycle. They reported slightly decreased pregnancy and live birth rates in women who had a diagnosis of depression or anxiety or took an antidepressant. No association was found for infertile women treated with antidepressants and fertility outcomes. The results of our study overlap with the results of the Swedish group. Since we did not evaluate fertility outcomes in our study, it is usual that two studies that did not match each other had non-common points. As a result, no significant net effects of pandemic-related anxiety and stress on IVF expectations have been detected (27).

A recent well-designed study by Barra et al (28) investigated the psychological status of infertile women who had invitro fertilization treatment interrupted or postponed because of the COVID-19 pandemic. They reported that 524 out of 646 participants completed the survey. The prevalence of anxiety and/or depression feelings was significantly higher in women more than 35 years and with a previous failed IVF attempt. The occurrence of these psychological symptoms was significantly associated with the time consuming on COVID19 related news every day and partner with evidence of some disorder and, in females, with a diagnosis of poor ovarian reserve, diagnosis of other infertility related disorders. The number of our patients who believed that delay in treatment due to pandemic would negatively affect their future fertility in elderly patients was significantly high. Similarly, the anxiety rates of our participants who had an underlying disease in infertility were higher. Our results and the results of the Barra were overlapping in many respects. According to the results obtained from both studies, the pandemic causes a subtle increase in the anxiety of IVF patients.

In the present style, we were unable to adjust for specific infertility diagnoses, as they may negatively affect the anxiety levels of IVF patients. Some diseases, such as polycystic ovary syndrome, need to be known beforehand as they can depress the patient (29). However, we gathered all infertile patients in the same group without any etiological discrimination and this is a handicap. Further, data were unavailable to adjust for some lifestyle factors in this study, including alcohol use, smoking habit, body mass index, and previous IVF attempt. Thus, the weak association we report between anxiety levels and IVF outcome may be due to unmeasured confounding. Hence, a more comprehensive study is needed to assess the factors underlying this link between covid-19 pandemic anxiety, and IVF outcome. In conclusion, although they were mostly stressed because of the covid-19 outbreak, many infertile women didn't change their IVF treatment plans during the outbreak. For this reason, IVF centers should give psychological support and help to couples during their IVF treatment in the pandemic era.
Acknowledgment: None

Competing interests: The authors declare that they have no competing interests.

Funding: This research did not receive any specific grant from any funding agency in the public, commercial, or not-forprofit sector.

Ethics approval and consent to participate: All participants signed informed written consent before being enrolled in the study. The study was reviewed and approved by the ethics committee of Nuh Naci Yazgan University (Ethics approval reference number: 2020/3, 20/08/2020). All procedures were performed according to the Declaration of Helsinki.

Availability of data and materials: The data supporting this study is available through the corresponding author upon reasonable request.

Authors contributions: $A Y$ and SK raised the presented idea and designed the study. SK conducted the analyses. AY and SK developed the first draft of the manuscript. All authors contributed to the writing of the paper, and have read and approved the final manuscript.

\section{References}

1. Cwikel J. Gidron Y. Sheiner E. Psychological interactions with infertility among women. Eur J Obstet Gynecol Reprod Biol. 2004;117(2):126-31. doi: 10.1016/j.ejogrb. 2004.05.004.

2. Roupa Z. Polikandrioti M. Sotiropoulou P. Faros E, Koulouri A. Wozniak G., et al. Causes of infertility in women at reproductive age. Health Science Journal. 2009;3(2):80-7.

3. Seibel MM, Taymor ML. Emotional aspects of infertility. Fertil Steril. 1982;37(2):137-45. Doi: 10.1016/s00150282 (16)46029-2.

4. Iammarrone E, Balet $\mathrm{R}$, Lower AM, Gillott C, Grudzinskas JG. Male infertility. Best Pract Res Clin Obstet Gynaecol. 2003;17(2):211-29. Doi: 10.1016/ s1521-6934(02)00147-5.

5. Geelhoed DW, Nayembil D, Asare K, Schagen van Leeuwen JH, van Roosmalen J. Infertility in rural Ghana. Int J Gynaecol Obstet. 2002;79(2):137-42. doi: 10.1016/ s0020-7292(02)00237-0.

6. Deyhoul N. Mohamaddoost T. Hosseini M. Infertility-related risk factors: a systematic review. Int J Women's Health Reprod Sci. 2017;5(1):24-9. doi: 10.15296/ijwhr.2017.05.

7. WHO, Coronavirus Disease (COVID-19) Dashboard, 2020. Available at https://covid19.who.int/.

8. Li R. Yin T. Fang F. Li Q. Chen J. Wang Y. et al. Potential risks of SARS-Cov-2 infection on reproductive health. Reprod Biomed Online. 2020;41(1):89-95. doi: 10.1016/ j.rbmo.2020.04.018.

9. Vaiarelli A. Bulletti C. Cimadomo D. Borini A. Alviggi C. Ajossa S. et al. COVID-19 and ART: the view of the 
Italian Society of Fertility and Sterility and Reproductive Medicine. Reprod Biomed Online. 2020;40(6):755-9. doi: 10.1016/j.rbmo.2020.04.003.

10. Zahra D. Sadatmahalleh SJ. Samaneh Y. Mahnaz BK. Anoshiravan K. Influential Factors on quality of life in married Iranian women during the Covid-19 pandemic in 2020: A Path Analysis. Research Square. 2020. doi:10. 21203/rs.3.rs-27439/v1.

11. Petok WD. High Anxiety: Helping your patients (and yourself) cope with the impact of COVID-19. Top Obstet Gynecol. 2020;40(8):1-7.

12. ESHRE COVID-19 Working Group, Vermeulen N, Ata B, Gianaroli L, Lundin K, Mocanu E, et al. A picture of medically assisted reproduction activities during the COVID-19 pandemic in Europe. Hum Reprod Open. 2020;2020(3):hoaa035. doi: 10.1093/hropen/hoaa035.

13. Veiga A. Gianaroli L. Ory S. Horton M. Feinberg E. Penzias A. Assisted reproduction and COVID-19: A joint statement of ASRM, ESHRE and IFFS. Fertil Steril. 2020;114(3):484-5. doi: 10.1016/j.fertnstert.2020.06.044.

14. Roy D. Tripathy S. Kar SK. Sharma N. Verma SK. Kaushal V. Study of knowledge, attitude, anxiety \& perceived mental healthcare need in Indian population during COVID-19 pandemic. Asian J Psychiatr. 2020;51:102083. doi: 10.1016/j.ajp.2020.102083.

15. ASRM-American Society for Reproductive Medicine COVID-19: Suggestions on managing patients who are undergoing infertility therapy or desiring pregnancy, 2020. Available at:https://www.asrm.org/news-and-publica-tions/news-and-research/press-releases-and-bulletins/covid-19-suggestions-on-managing-patients-whoare-undergoing-infertility-therapy-or-desiring-pregnancy/

16. ESHRE-European Society for Human Reproduction and Embryology, Coronavirus Covid-19: ESHRE statement on pregnancy and conception, 2020.Available at: https:/www.eshre.eu/Press-Room/ESHRE-News.

17. De Santis L. Anastasi A. Cimadomo D. Klinger FG. Licata E. Pisaturo V. et al. COVID-19: The perspective of Italian embryologists managing the IVF laboratory in pandemic emergency. Hum Reprod. 2020;35(4):1004-5. doi: 10.1093/humrep/deaa074.

18. Pomeroy KO. Schiewe MC. Cryopreservation and IVF in the time of Covid-19: what is the best good tissue practice (GTP)? J Assist Reprod Genet. 2020;37(10):2393-8. doi: 10.1007/s10815-020-01904-5.

19. Andrabi SW. Jaffar M. Arora PR. COVID-19: New adaptation for IVF laboratory protocols. JBRA Assist Reprod.
2020;24(3):358-61. doi: 10.5935/1518-0557.20200054.

20. Choucair F. Younis N. Hourani A. IVF laboratory COVID-19 pandemic response plan: a roadmap. Middle East Fertil Soc J. 2020;25(1):31. doi: 10.1186/s43043020-00043-2.

21. Anifandis G. Messini CI. Daponte A. Messinis IE. COVID-19 and fertility: a virtual reality. Reprod Biomed Online. 2020;41(2):157-9. doi: 10.1016/j.rbmo.2020. 05.001 .

22. Simopoulou M. Sfakianoudis K. Giannelou P. Rapani A. Siristatidis C. Bakas P. et al. Navigating assisted reproduction treatment in the time of COVID-19: concerns and considerations. J Assist Reprod Genet. 2020;37(11):26638. doi: 10.1007/s10815-020-01942-z.

23. Sobral MP. Costa ME. Schmidt L. Martins MV. COMPI Fertility Problem Stress Scales is a brief, valid and reliable tool for assessing stress in patients seeking treatment. Hum Reprod. 2017;32(2):375-82. doi: 10.1093/ hum$\mathrm{rep} / \mathrm{dew} 315$.

24. Katsohiraki M. Poulopoulou S. Fyrfiris N. Koutelekos I. Tsiotinou P. Adam O. Vasilopoulou E. Kapritsou M. Evaluating Preoperative Anxiety Levels in Patients Undergoing Breast Cancer Surgery. Asia Pac J Oncol Nurs. 2020 Sep 14;7(4):361-364. doi: 10.4103/apjon. apjon-31-20.

25. Rooney KL. Domar AD. The relationship between stress and infertility. Dialogues Clin Neurosci. 2018;20(1):41-7. doi: 10.31887/DCNS.2018.20.1/klrooney.

26. Vitale SG. La Rosa VL. Rapisarda AM. Laganà AS. Psychology of infertility and assisted reproductive treatment: The Italian situation. J Psychosom Obstet Gynaecol. 2017;38(1):1-3. doi: 10.1080/0167482X.2016.1244184.

27. Cesta CE.Viktorin A. Olsson H. Johansson V. Sjölander A. Bergh C. et al. Depression, anxiety, and antidepressant treatment in women: association with in vitro fertilization outcome. Fertil Steril. 2016;105(6):1594-1602.e3. doi: 10.1016/j.fertnstert.2016.01.036.

28. Barra F. La Rosa VL. Vitale SG. Commodari E. Altieri M. Scala C. et al. Psychological status of infertile patients who had in vitro fertilization treatment interrupted or postponed due to COVID-19 pandemic: a cross-sectional study. J Psychosom Obstet Gynaecol. 2020:1-8. doi: 10.1080/0167482X.2020.1853095.

29. Barry JA. Kuczmierczyk AR. Hardiman PJ. Anxiety and depression in polycystic ovary syndrome: a systematic review and meta-analysis. Hum Reprod. 2011;26(9):244251. doi: 10.1093/humrep/der197. 